\title{
Tailor Able Optical Properties of Silver Nanoparticles from Butea Monosperma Plant Extract
}

\author{
Ujwala S. Tayade ${ }^{1}$, Amulrao U. Borse ${ }^{1 *}$, Jyotsna S. Meshram $^{2^{*}}$ \\ ${ }^{1}$ School of Chemical Sciences, North Maharashtra University, Jalgaon (M.S.), India \\ ${ }^{2}$ Department of Chemistry, Rashtrasant Tukadoji Maharaj University, Nagpur (M.S.), India \\ Email: drjsmeshram@gmail.com,amulborse@gmail.com
}

\begin{abstract}
Nowdays Silver nanoparticles are in increasing commercial demands due to their enormous application in wide range of scientific fields, such as medicines, catalysis, electronics, chemistry and energy. Herein we have reported a very simple and green approach of chemical reduction method for nanoparticle synthesis. The plant extract of Butea monosperma is used as reducing agent as well as capping agent. For confirmation of essential phytochemicals present in extract screening of phytochemicals such as Proteins, Flavonoids, Terpenoids, Cardiac glycosides and Tannins etc. has been carried out in the present study. The UV- Visible spectroscopy has been used to determine Surface Plasmon Resonance (SPR) and Infrared Spectroscopy (IR) to confirm functional groups. From the Absorbance the band gap values have been calculated which are useful in soft electronic devices.
\end{abstract}

Keywords: Green approach, capping agent, phytoconstituent, surface plasmon resonance, band gap

\section{Introduction}

The role of plant materials as medicines owing the presence of crucial Phytoconstituent and the specific action to cure various diseases without affecting the other organs plays a crucial role in Science, research and development. The nanotechnology research focusing on plant materials used to synthesis of nanomaterial is on rise. The particles with size were less than $100 \mathrm{~nm}$, Nanoparticles (NPs). Entirely novel and enhanced characteristics such as size, distribution and morphology are revealed by these particles in comparison to the larger particles of the bulk material from which they can be prepared [1]. Nanoparticles of noble metals like gold, silver and platinum are well - recognized to have significant applications in electronics, magnetic, optoelectronics and information storage devices [2-5]. One such important member of the noble metal NPs are silver ( $\mathrm{Ag} \mathrm{NPs}$ ), widely used in shampoos, soaps, cosmetics, toothpastes, medicinal and pharmaceutical products $[6,7]$. The universal demand of silver nanoparticles is larger than the production rate and the pioneering ideas are more promising for nanoparticles synthesis such as more economic and sustainable routes (Green methods of nanoparticles synthesis). Different approaches available for the synthesis of silver nanoparticles are chemical [8], electrochemical [9], radiation [10], photochemical methods [11] and bio based methods [12-14]. All mentioned techniques of silver NPs preparation, plant-mediated bio mimetic synthesis of silver nanoparticle is considered a widely use technology or rapid production of silver nanoparticles for successfully obtaining the excessive need and current market demand and resulting reduction of harmful chemicals in synthesis of nanoparticles. Studies have shown that Alfalfa roots can absorb Ag (0) from agar medium and able to transport it to the plant shoot in the same state of oxidation [15]. Ag NPs were also obtained using Jatropha curcas [16], Aloe Vera [17], Acalyphaindica [18], Garcinia mangostana leaf extracts [19], Crataegus douglasii fruit extract [20] as well as wide range of other plant extracts [21] as reducing agent. Herein we have developed a rapid, eco-friendly and convenient green method for the synthesis of silver nanoparticles from silver nitrate using Butea monosperma plant extract as a reducing agent and capping agent merely at room temperature. Ag NPs were characterized and studied in details with all of their properties significant to current science and prevailing technologies. Silver nanoparticles have attracted more and more attention because of their fascinating electrical, thermal and optical 
properties. Silver has the highest electrical conductivity $\left(6.3 \times 10^{7} \mathrm{~S} / \mathrm{m}\right)$ among all the metals, by virtue of which Ag Nanoparticles are considered as very promising candidates in flexible electronics [22-24].

\section{Methods}

\section{Preparation of the leaf extract}

The Indian medicinal plant, Butea monosperma is selected from Maharashtra, India because of its cost effectiveness, ease of availability and medicinal properties. Fresh and healthy flowers were collected locally and rinsed thoroughly first with tap water followed by distilled water to remove all the dust and unwanted visible particles, cut into small pieces and dried at room temperature. About 10 gm. of these finely incised flowers of plant type were weighed separately and transferred into $250 \mathrm{~mL}$ flask containing $100 \mathrm{~mL}$ distilled water and boiled for about $10 \mathrm{~min}$. The extract was then filtered thrice through Whatman No. 1 filter paper to remove particulate matter and to get clear solution which was then refrigerated $\left(4^{\circ} \mathrm{C}\right)$ for further experiments. In each step of the experiment, sterility conditions were maintained for the effectiveness and accuracy in results without contamination.

\section{Phytochemical Analysis}

\section{Qualitative Analysis}

Following standard protocols were used for qualitative analysis of samples to check for the presence of Alkaloids, Carbohydrates, Cardiac glycosides, Flavonoid, Phenols, Saponins, Tannins, Terpenoids, Quinones and Proteins respectively.

1. Test for Flavonoids: $2 \mathrm{ml}$ of each extract was added with few drops of $20 \%$ sodium hydroxide, formation of intense yellow colour is observed. To this, few drops of $70 \%$ dilute hydrochloric acid were added and yellow colour was disappeared which indicates the presence of flavonoids in the sample extract.

2. Test for Alkaloids: To $1 \mathrm{ml}$ of each extract, $1 \mathrm{ml}$ of marquis reagent, $2 \mathrm{ml}$ of concentrated sulphuric acid and few drops of $40 \%$ formaldehyde were added and mixed, appearance of dark orange or purple colour indicates the presence of alkaloids.

3. Test for Saponins: To $2 \mathrm{ml}$ of each extract, $6 \mathrm{ml}$ of distilled water were added and shaken vigorously; formation of bubbles or persistent foam indicates the presence of Saponins.

4. Test for Tannins: To $2 \mathrm{ml}$ of each extract, $10 \%$ of alcoholic ferric chloride was added; formation of brownish blue or black colour indicates the presence of tannins.

5. Test for Phenols: To $2 \mathrm{ml}$ of each extract, $2 \mathrm{ml}$ of $5 \%$ aqueous ferric chloride was added; formation of blue colour indicates the presence of phenols in the sample extract.

6. Test for Proteins: To $2 \mathrm{ml}$ of each extract, $1 \mathrm{ml}$ of $40 \%$ sodium hydroxide and few drops of $1 \%$ copper sulphate were added; formation of violet colour indicates the presence of peptide linkage molecules in the sample extract.

7. Test for Cardiac Glycosides: To $1 \mathrm{ml}$ of each extract, $0.5 \mathrm{ml}$ of glacial acetic acid and 3 drops of $1 \%$ aqueous ferric chloride solution were added and formation of brown ring at the interface indicates the presence of cardiac glycosides in the sample extract.

8. Test for Terpenoids: Take $1 \mathrm{ml}$ of extract of each solvent and add $0.5 \mathrm{ml}$ of chloroform followed by a few drops of concentrated sulphuric acid, formation of reddish brown precipitate indicates the presence of Terpenoids in the extract.

9. Test for Carbohydrates: Take $1 \mathrm{ml}$ of extract, add few drops of Molish reagent and then add $1 \mathrm{ml}$ of concentrated sulphuric acid at the side of the tubes. The mixture was then allowed to stand for 2 to 3 minutes. Formation of red or dull violet colour indicates the presence of carbohydrates in the sample extract.

\section{Preparation of Silver Nanoparticles Using Butea Monosperma Extract}

Aqueous solution $(1 \mathrm{mM})$ of Silver nitrate $\left(\mathrm{AgNO}_{3}\right)$ and leaf extract was added for the reduction of $\mathrm{Ag}$ ions. The mixture was kept on Magnetic Stirrer for $30 \mathrm{~min}$ at room temperature. In the meantime, colour change of the mixture from faint light to yellow- brown to colloidal brown was monitored 
periodically (time and colour change was recorded along with periodic sampling and scanning by UVVisible Spectrometer ) for maximum $30 \mathrm{~min}($ Figure 1). The reaction was carried out in darkness to avoid photo activation of $\mathrm{AgNO}_{3}$ at room temperature. After formation of $\mathrm{Ag}$ Nanoparticles centrifugation was carried at $3200 \mathrm{rpm}$ for $10 \mathrm{~min}$ washed twice with deionized water to remove any impurities present.
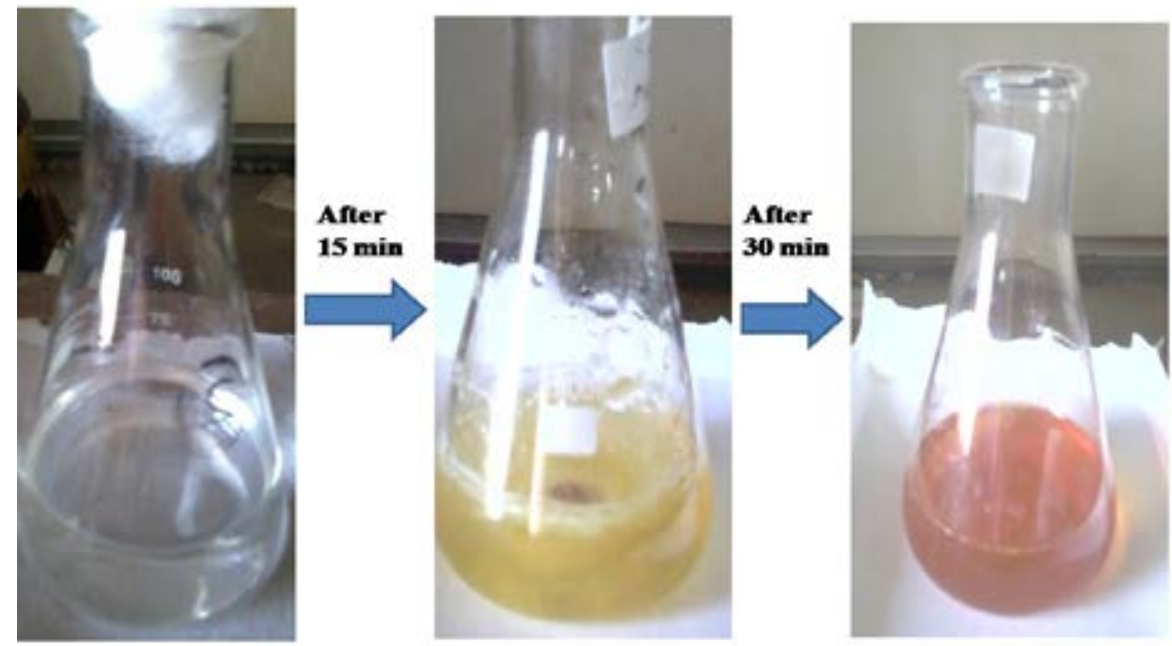

Figure 1. Synthesis of silver nanoparticles

\section{Instrumentation}

Infrared spectroscopy (FT-IR) was measured on a Shimadzu FTIR-8400 spectrometer $400 \mathrm{~cm}^{-1}$ to $4000 \mathrm{~cm}^{-1}$ at room temperature. The Ultra Violet-Visible spectroscopy (UV-Vis) absorption study was performed at room temperature in the wavelength range of $200-800 \mathrm{~nm}$ on a UV-Vis spectrometer Shimadzu UV-1700.

\section{Characterization}

UV-Visible analysis (Figure 2 \& Figure 3)

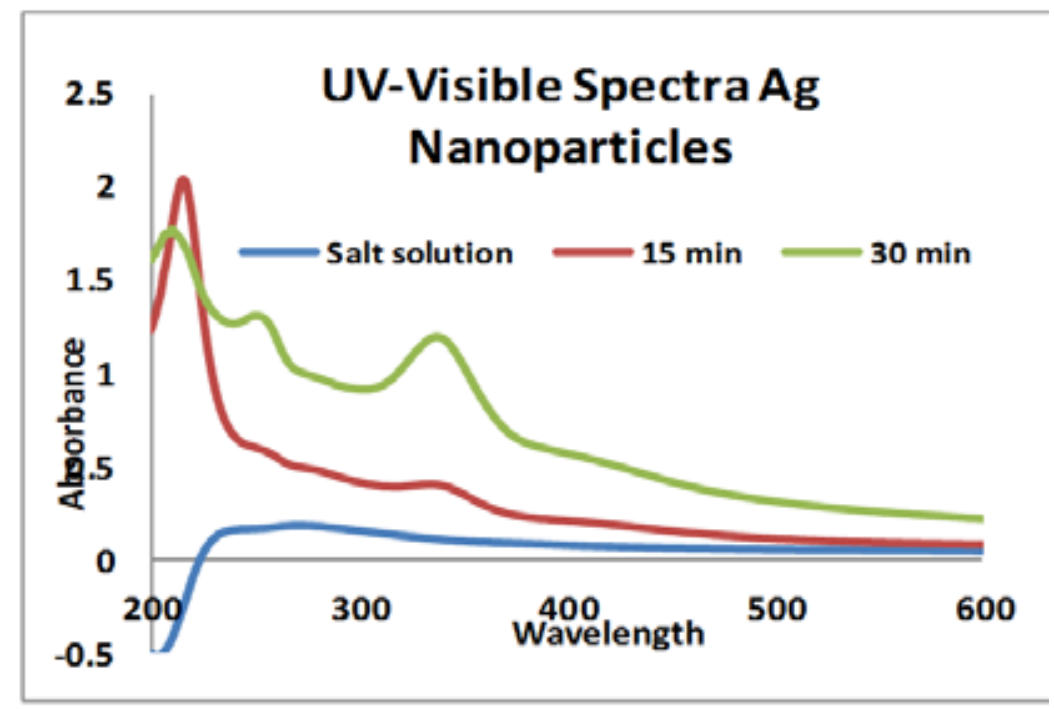

Figure 2 UV-visible analysis of silver nanoparticles 


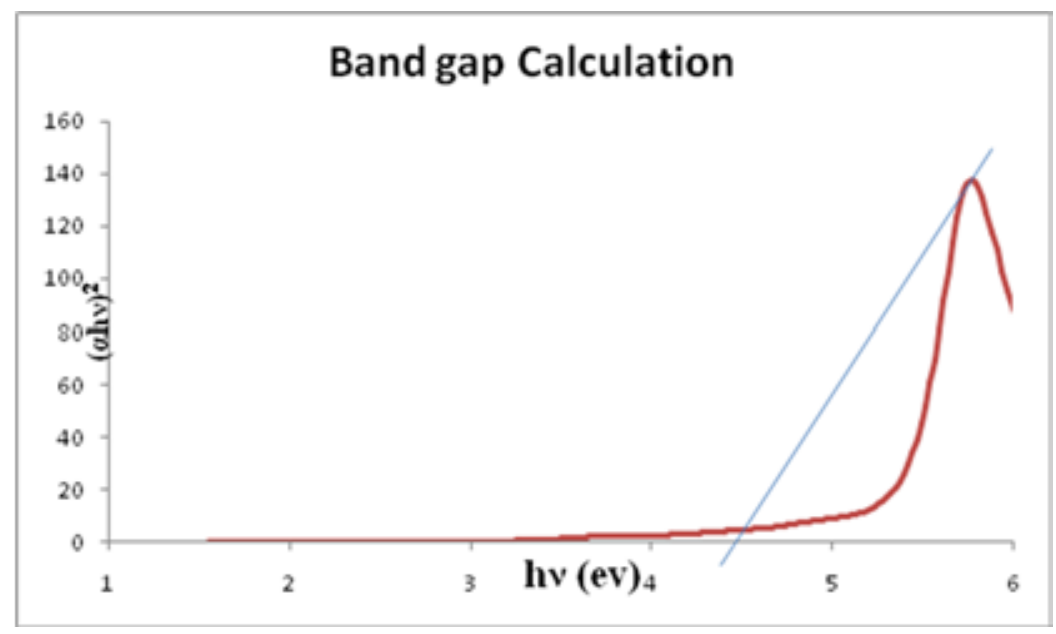

Figure 3 Band gap calculation of silver nanoparticles

FTIR analysis (Figure 4)

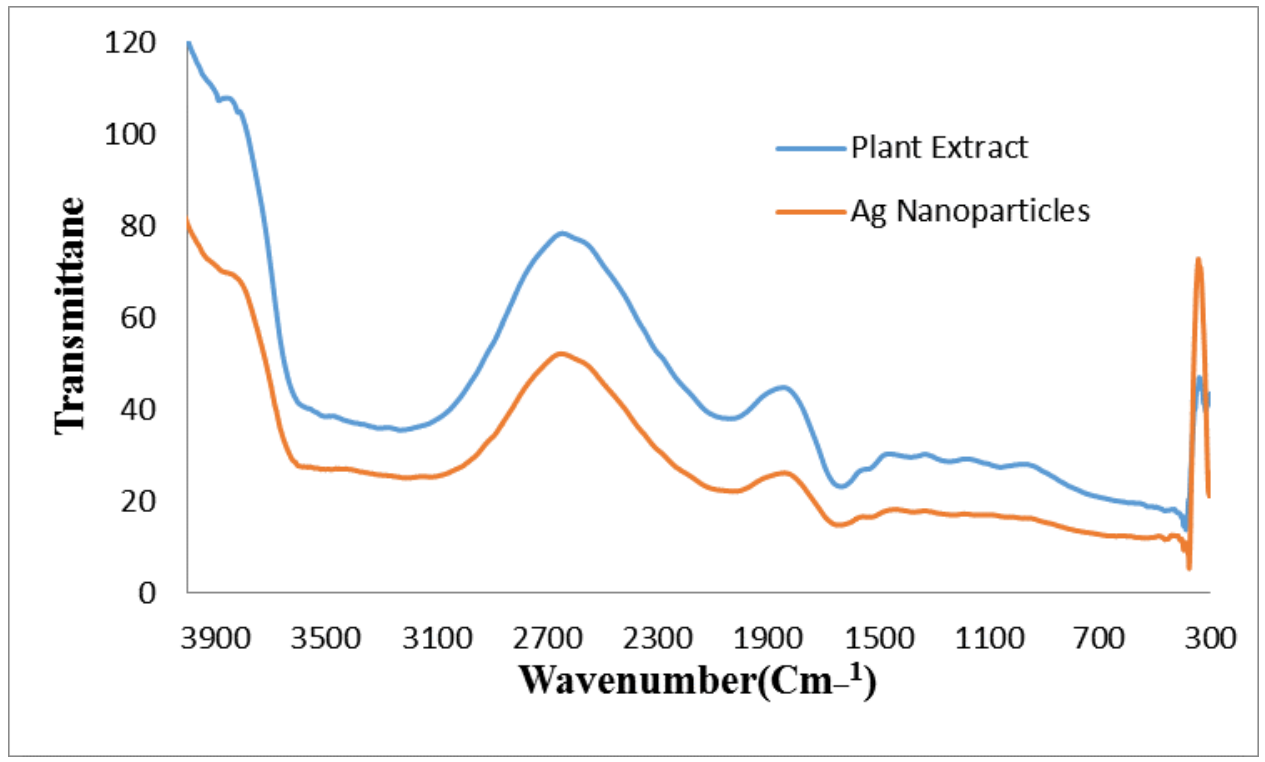

Figure 4 FTIR analysis of silver nanoparticles

Phytochemical Screening (Table 1)

Table 1 Phytochemical screening

\begin{tabular}{llll}
\hline Sr.no. & Phytochemicals test & Procedure & Present /Absent \\
\hline 1 & Carbohydrates & Plant extract + 1-naphthol + Conc.Sulphuric acid & - \\
2 & Protein & Plant extract + copper sulphate solution + KOH solution & + \\
3 & Alkaloids & Plant extract + Meyers Reagent & - \\
4 & Flavonoid & 2ml plant extract + ammonium hydroxide solution & + \\
5 & Terpenoids & 2ml plant extract + Chloroform + Conc. sulphuric acid & + \\
6 & Cardiac Glycosidase & 2ml plant extract +3 ml of Chloroform $+10 \%$ ammonia & + \\
& & solution & + \\
7 & Tannins & Plant extract + few drops of lead acetate & - \\
\hline
\end{tabular}




\section{Results and Discussion}

In this plant extract performing the various tests for phytochemical screening which indicates existence of Proteins, Flavonoids, Terpenoids, Cardiac Glycosidase and Tannins etc. plays more fundamental role in bio based nanoparticles synthesis.

\subsection{UV-Visible Spectral Analysis}

The Bio based reduction of Silver in the reaction mixture monitored by periodic sampling at regular interval by UV-Visible Spectroscopy. The metal ion solution does not show any change in its absorbance also not largest. But the reaction mixture at 15 and $30 \mathrm{~min}$ respectively shows $340 \mathrm{~nm}$ and $420 \mathrm{~nm}$ which is Characteristic values of Silver nitrate solution and Surface Plasmon Resonance Analysis by Spectrophotometer was made up to $30 \mathrm{~min}$.

\subsection{Band Gap Calculation}

The band gap value of Silver nanoparticles can be calculated by using following equation,

$$
\mathrm{E}_{\mathrm{g}}=1240 / \lambda
$$

The band gap Value comes out which is $4.36 \mathrm{eV}$.

\subsection{Fourier Transfer Infrared Spectroscopy}

Some functional groups in silver nanoparticles are confirmed by FTIR analysis. The band values at 3398 $\mathrm{cm}^{-1}$, characteristic of $-\mathrm{OH}$ and -NH Vibrational frequencies. Vibrational peaks between 2899 and 2977 $\mathrm{cm}^{-1}$ were characteristic frequency of $-\mathrm{CH}$ Symmetrical vibration of saturated hydrocarbons. The Vibrational frequency of C-O observed in the spectra of the extract at 1047 and $1087 \mathrm{~cm}^{-1}$. Deviation from this region to higher wavenumber was observed indicating secondary amide. The peaks were sharper than the frequency of $-\mathrm{OH}$ peaks due to reduction in hydrogen bonds which increased with electro negativity. The sharp peak observed below $500 \mathrm{~cm}^{-1}$ indicates presence of silver nanoparticles formation.

\section{Conclusion}

In this work extract of Butea monosperma plants carried out and their phytochemical analysis was also carried which indicates the presence of Proteins, Flavonoids, Terpenoids, Cardiac Glycosidase and Tannins etc. plays more fundamental role in bio based nanoparticles synthesis. The synthesized nanoparticles show good optical properties and tailor ability for applications having band gap value 4.36 $\mathrm{eV}$. It is very simple and less time - consuming method of nanoparticles synthesis.

\section{References}

1. Van den Wildenberg W. Roadmap report on nanoparticles. Wand W Espan Barcelona, Spain, Vol.57. 2005.

2. M. Grätzel Photo electrochemical cells. Nature, Vol.414, pp.338-44, 2001.

3. M.Okuda, Y., Kobayashi, K. Suzuki, K.Sonoda, T.Kondoh, A.Wagawa, A. Kondo and H.Yoshimura, "Selforganized inorganic nanoparticle arrays on protein lattices," Nano letters, Vol.5, pp.991-993, 2005.

4. J. Dai and M.L.Bruening," Catalytic nanoparticles formed by reduction of metal ions in multilayered polyelectrolyte films," Nano Letters, Vol.2, pp.497-501, 2002.

5. C.B.Murray, S.Sun, Doyle and T.Betley,"Mon disperse 3d transition-metal (Co, Ni, Fe) nanoparticles and their assembly into nanoparticle super lattices," Materials Bulletin, Vol.26, pp.985-991, 2001.

6.R.Bhattacharya and P.Mukherjee, "Biological properties of naked metal nanoparticles," Advanced drug delivery reviews, Vol.60,pp.1289-1306, 2008.

7. D.R.Bhumkar, H.M.Joshi, M.Sastry and V.B.Pokharkar, "Chitosan reduced gold nanoparticles as novel carriers 
for trans mucosal delivery of insulin," Pharmaceutical research, Vol.24, pp.1415-1426, 2007.

8. Y.Sun, Y. Yin, B.T. Mayer's, T. Herrick's and Y. Xia, "Uniform silver nanowires synthesis by reducing $\mathrm{AgNO}_{3}$ with ethylene glycol in the presence of seeds and poly (vinyl pyrrolidone)," Chemistry of Materials, Vol.14, pp.4736-4745, 2002.

9. B.Yin, H.Ma. S. Wang and S.Chen, "Electrochemical synthesis of silver nanoparticles under protection of poly (N-vinylpyrrolidone)," The Journal of Physical Chemistry B, Vol.107, pp.8898-8904, 2003.

10.N.M.Dimitrijevic, D.M.Bartels, C.D.Jonah, K.Takahashi and T.Rajh, "Radiolytically Induced Formation and Optical Absorption Spectra of Colloidal Silver Nanoparticles in Supercritical Ethane," The Journal of Physical Chemistry B, Vol.105, pp.954-959, 2001.

11. A.Callegari, D. Tonti, and M.Chergui, "Photo chemically grown silver nanoparticles with wavelength-controlled size and shape," Nano Letters, Vol 3, pp.1565-1568, 2003.

12. L.Zhang, Y.Shen, A.Xie, B. Jin and Q.Zhang, "One-step synthesis of mono disperse silver nanoparticles beneath vitamin E Langmuir monolayers," The Journal of Physical Chemistry B, Vol 110, pp.6615-6620, 2006.

13. A.Swami, P.R.Selvakannan, R.Pasricha and M.Sastry, "One-step synthesis of ordered two-dimensional assemblies of silver nanoparticles by the spontaneous reduction of silver ions by pentadecyl phenol Langmuir monolayers," The Journal of Physical Chemistry B, Vol 108, pp.19269-19275, 2004.

14. R.R.Naik, S.J.Stringer, G.Agrwal, S.E.Jones and M.O.Stone, "Biomimetic synthesis and patterning of silver nanoparticles," Nature materials, Vol 1, pp.169-172, 2002.

15. J.L.Gardea-Torresdey, J.G.Parsons, H.Troiani and M.Jose-Yacaman, "Alfalfa sprouts: a natural source for the synthesis of silver nanoparticles," Langmuir, Vol 19, pp.1357-1361, 2003.

16. H.Bar, D.K. Bhui, G.P.Sahoo, P. Sarkar and A.Misra, "Green synthesis of silver nanoparticles using latex of Jatropha curcas," Colloids and surfaces A: Physicochemical and engineering aspects, Vol 339, pp.134-139, 2009.

17. S.P.Chandran, M. Chaudhary, R.Pasricha, A.Ahmad and M.Sastry, "Synthesis of gold Nano triangles and silver nanoparticles using Aloe Vera plant extract," Biotechnology progress, Vol 22, pp.577-583, 2006.

18.C.Krishnaraj, E.G.Jagan, S. Rajasekar, P. Selvakumar, and N.Mohan, "Synthesis of silver nanoparticles using Acalypha indica leaf extracts and its antibacterial activity against water borne pathogens," Colloids and Surfaces B: Bio interfaces, Vol 76, pp.50-56,2010.

19.T.Z.Xin, N.Jeyakumar and S.A.Dhanaraj, "Biosynthesis of silver nanoparticles using mangos teen leaf extract and evaluation of their antimicrobial activities," Journal of Saudi Chemical Society, Vol 15, pp.113-120, 2011.

20. Ghaffari-Moghaddam and Hadi-Dabanlou, "Plant mediated green synthesis and antibacterial activity of silver nanoparticles using Crataegus douglasii fruit extract," Journal of Industrial and Engineering Chemistry, Vol 20, pp.739-744, 2014.

21. M.Ghaffari-Moghaddam, R. Hadi-Dabanlou, M.Rakhshanipour and K.Shameli, "Green synthesis of silver nanoparticles using plant extracts," Korean Journal of Chemical Engineering, Vol 31, pp.548-557, 2014.

22. D.Azulai, T.Belenkova, H.Gilon, Z. Barkay and G.Markovich, "Transparent metal nanowire thin films prepared in mesostructured templates," Nano letters, Vol 9, pp.4246-4249, 2009.

23. Y.Sun, "Silver nanowires-unique templates for functional nanostructures," Nano scale, Vol 2, pp.1626-1642, 2010.

24. S.De, P.E. Lyons, E.M. Doherty, Nirmalraj, J.J.Boland and J.N.Coleman, "Silver nanowire networks as flexible, transparent, conducting films: extremely high DC to optical conductivity ratios," ACS Nano, Vol 3, pp.1767-1774, 2009. 